\title{
'High' achievers? Cannabis access and academic performance
}

Citation for published version (APA):

Marie, O., \& Zölitz, U. N. (2015). 'High' achievers? Cannabis access and academic performance. ROA. ROA Research Memoranda No. 004 https://doi.org/10.26481/umaror.2015004

Document status and date:

Published: 01/01/2015

DOI:

10.26481/umaror.2015004

Document Version:

Publisher's PDF, also known as Version of record

\section{Please check the document version of this publication:}

- A submitted manuscript is the version of the article upon submission and before peer-review. There can be important differences between the submitted version and the official published version of record.

People interested in the research are advised to contact the author for the final version of the publication, or visit the DOI to the publisher's website.

- The final author version and the galley proof are versions of the publication after peer review.

- The final published version features the final layout of the paper including the volume, issue and page numbers.

Link to publication

\footnotetext{
General rights rights.

- You may freely distribute the URL identifying the publication in the public portal. please follow below link for the End User Agreement:

www.umlib.nl/taverne-license

Take down policy

If you believe that this document breaches copyright please contact us at:

repository@maastrichtuniversity.nl

providing details and we will investigate your claim.
}

Copyright and moral rights for the publications made accessible in the public portal are retained by the authors and/or other copyright owners and it is a condition of accessing publications that users recognise and abide by the legal requirements associated with these

- Users may download and print one copy of any publication from the public portal for the purpose of private study or research.

- You may not further distribute the material or use it for any profit-making activity or commercial gain

If the publication is distributed under the terms of Article $25 \mathrm{fa}$ of the Dutch Copyright Act, indicated by the "Taverne" license above, 


\section{'High' achievers? \\ Cannabis access and academic performance}

Olivier Marie

Ulf Zölitz

\section{ROA Research Memorandum}

ROA-RM-2015/4

Researchcentrum voor Onderwijs en Arbeidsmarkt | ROA

Research Centre for Education and the Labour Market | ROA 


\section{'High' achievers? \\ Cannabis access and academic performance}

Olivier Marie

Ulf Zölitz

ROA-RM-2015/4*

March 2015

Research Centre for Education and the Labour Market

Maastricht University

P.O. Box 616, 6200 MD Maastricht, The Netherlands

$\mathrm{T}+31433883647 \mathrm{~F}+31433884914$

secretary-roa-sbe@maastrichtuniversity.nl

www.roa.nl

* The ROA Research Memorandum Series was created in order to make research results available for discussion, before those results are submitted for publication in journals. 


\section{Abstract}

\section{'High' achievers? Cannabis access and academic performance**}

This paper investigates how legal cannabis access affects student performance. Identification comes from an exceptional policy introduced in the city of Maastricht which discriminated legal access based on individuals' nationality. We apply a differencein-difference approach using administrative panel data on over 54,000 course grades of local students enrolled at Maastricht University before and during the partial cannabis prohibition. We find that the academic performance of students who are no longer legally permitted to buy cannabis increases substantially. Grade improvements are driven by younger students, and the effects are stronger for women and low performers. In line with how THC consumption affects cognitive functioning, we find that performance gains are larger for courses that require more numerical/mathematical skills. We investigate the underlying channels using students' course evaluations and present suggestive evidence that performance gains are driven by improved understanding of material rather than changes in students' study effort.

JEL classification: I18, I20, K42

Keywords: cannabis, legalization, student performance

Olivier Marie

Department of Economics/ROA

Maastricht University

P.O. Box 616

6200 MD Maastricht

The Netherlands

o.marie@maastrichtuniversity.nl and CEP, IZA and CESIfo
Ulf Zölitz

Institute for the Study of Labor - IZA

P.O. Box 7240

D-53072 Bonn

Germany

zoelitz@iza.org

and Department of Economics, Maastricht University

\footnotetext{
** We thank Dan Black, Daniel Hammermesh, Brian Jacob, Paul Lemmens, Daniel Mejia, Rosalie Pacula, Nicolas Salamanca, participants of the 2014 NBER-SI, the 4th AL CAPONE meeting and seminar participants at CPB, the Hague, IZA Bonn, NED Amsterdam, Northwestern University, RAND and the University of Chicago for useful comments and suggestions. We further thank Joël Castermans, Sanne Klasen and Kim Schippers from the SBE Scheduling Department, Sylvie Kersten from the SBE Exams Office, and Paul Jacobs from the Educational Research and Development Department for providing data and valuable background information. Marie is grateful for financial support for this research from the Netherlands Organization for Scientific Research (NWO Veni 451.12.005).
} 


\section{$1 \quad$ Introduction}

Public policy and opinion regarding the legalization of cannabis has reached a tipping point. In the US, 20 states have now passed laws allowing its medical use, and 14 others have taken steps to decriminalize consumption by some degree. In 2014, Colorado and Washington legalized sale and possession of cannabis for recreational use after a popular vote. Alaska and Arizona should follow suit in 2015 , and several other states are currently reconsidering their cannabis laws. Uruguay is planning to become the first nation in the world to fully legalize all aspects of the cannabis trade including cannabis cultivation, wholesale, retail and consumption. The Americas are starting to 'catch up' with the more liberal approach to soft drug policy in countries such as the Netherlands, where cannabis consumption has been decriminalized for almost four decades. Despite this development, little is known about many of the - perhaps unintended - consequences of legalization. This paper contributes to the ongoing legalization discussion by showing that a change in legal cannabis access strongly affected student performance through adjustments in their consumption behavior.

Proponents of cannabis legalization have put forward the general failure of the long running 'war on drugs' and the huge cost it imposes on the criminal justice system as an argument in favor of finding alternatives to drug prohibition (Donohue 2013). Also, legalization would undermine illegal markets and protect low level users from associated risks, such as contact with dealers that sell other types of drugs. Opponents of cannabis legalization often argue that making access to cannabis easier and more acceptable via legalization could push more marginal individuals to become consumers. This could in turn lead to an increase in the number of individuals suffering from adverse health, educational, and labor market outcomes associated with regular cannabis use (Cobb-Clark et al. 2015; Hall 2015 and Van Ours and Williams, 2015).

While both sides of the legalization debate make plausible arguments, the actual effect that policies which change cannabis access have on consumption decisions and on outcomes 
affected by consumption remains largely ambiguous. The lack of clear empirical evidence is the result of identification problems which mostly prevent a causal interpretation of most existing results. The principal issue is that drug policy changes are unlikely to be implemented exogenously and are usually the result of a longer process of societal change. When policy changes take place, they usually affect all individuals at the same time, which makes it impossible to fully disentangle treatment effects from underlying time trends in consumption - trends which may have caused the policy change in the first place. These issues cast doubt on the validity of results obtained from studies using cohort or state level variation, where the necessary ceteris paribus conditions for identification often do not hold. ${ }^{1}$

In this paper, we exploit a unique natural experiment to obtain causal estimates of the effect of a change in legal cannabis access on college student performance. We exploit a temporary policy change in the city of Maastricht in the Netherlands that locally restricted legal access to cannabis based on nationality. By looking at changes in university achievements of students who were potentially affected by the policy against those of their peers who were unaffected, we isolate the impact of the policy on a measure of individual productivity which is likely to be strongly affected by cannabis consumption. Importantly, students were not the intended target of the discriminatory policy, which was originally introduced to combat drug tourism in the city. This "partial-prohibition" allows us to apply a difference-in-difference approach across nationality groups of students observed before and during the discriminatory policy. To eliminate concerns about unobserved heterogeneity, we exploit the panel nature of our data and apply student fixed effects to identify performance changes resulting from the 'cannabis prohibition' using within-individual variation. From a medical perspective, there is little doubt about the negative short run effects of cannabis consumption. Studies have repeatedly shown that cognitive functions are strongly impaired by

\footnotetext{
${ }^{1}$ The review of Pacula and Sevigny (2014) discusses a number of recent articles using state level difference-indifferences approaches to assess how the introduction of medical cannabis laws in the US affect consumption behaviour and other outcomes. The review report mixed findings and highlights multiple reasons (e.g., changes in police force behavior) for why results might not have a causal interpretation.
} 
cannabis consumption in the short run. $^{2}$ We therefore expect changes in cannabis consumption behavior, brought about by the access restriction scheme studied here, to be reflected in the academic performance of the students affected. This rationalizes our reduced form approach, which looks directly at student productivity, rather than (unavailable) changes in consumption, as an outcome. ${ }^{3}$

Our main finding is that the temporary restriction of legal cannabis access had a strong positive effect on course grades of the affected students. These individuals performed, on average, 9 percent of a standard deviation better and were 5.4 percent more likely to pass courses when they were banned from entering cannabis-shops ('coffeeshops'). Importantly, we do not detect a change in dropout probability, which could have created complex composition effects. Sub-group analysis reveals that these effects are somewhat stronger for women than men and that they are driven by younger and lower performing students. This can be explained by baseline differences in consumption rates or differences in marginal compliance with the prohibition. ${ }^{4}$ We also find some evidence for a social spillover of the cannabis restriction: Treated students in sections with a higher fraction of treated peers become marginally more likely to pass their courses. We however reject that teachers' legal access to cannabis has an impact on their students' performance. Finally, both time and nationality placebo analyses reassure us that the effect on performance is really a reflection of the policy effect.

\footnotetext{
${ }^{2}$ Bossong et al. $(2012,2013)$ carry out randomized control trials where subjects have to carry simple cognitive task and find that "performance was impaired after THC administration, reflected in both an increase in false alarms and a reduction in detected targets."

${ }^{3}$ This reduced form approach avoids serious measurement problems with usual measures of drug consumption, since it does not have to rely on self-reported consumption or police seizures which are likely to be correlated with changes in the legal status of this substance. Another highly relevant short run outcome that might be affected by changes in soft drug access policy is criminal activity. This is perhaps not as 'clean' an externality as productivity since it is the sum of changes in behaviour of all agents concerned: consumers, dealers, and the police. Adda, McConnell, and Rasul (2014) are the only ones to have attempted to disentangle the various channels from this complex relationship.

${ }^{4}$ It might simply be more costly for women to engage in the illegal commerce that is necessary to obtain access during the "cannabis-prohibition".
} 
In order to assess whether the changes in performance we detect really stem from change in students' cannabis consumption, we test whether our results are consistent with what is known about the impact of THC on human brain functioning and learning. First, previous research has documented that cannabis consumption most negatively impacts quantitative thinking and math-based tasks (Block and Ghoneim [1993] and Pacula [2003]). Therefore, we split all courses depending on whether they are described as requiring numerical skills or not. We then test if such skills are affected differentially and find that the policy effect is five times larger for courses requiring numerical/mathematical skills - a result in line with the existing evidence on the association between cannabis use and cognitive functioning. Second, to provide some suggestive evidence on the underlying channels, we make use of evaluations which students are asked to fill in for each course. In these evaluations, students report their own level of effort, overall understanding, and the perceived quality of the course and teachers. We find no change in reported study hours, which suggests that we can eliminate effort adjustments as one channel of our results. We do find an increase in the reported "overall understanding" of the course content when the policy was in place.

Finally, we put our main finding in perspective with the estimated impact of other interventions on college student performance. Most relevant is that our change in legal cannabis access has almost exactly the same effect as students reaching the age when alcohol consumption is permitted in the US (Carrel, Hoekstra, and West [2011] and Lindo, Swensen and Waddell [2013]). To better interpret our results, we carried out a survey among current students at Maastricht University which revealed that over half had consumed cannabis in the past year. Using this to proxy the size of the potentially treated population and applying various compliance rates suggests that the prohibition policy had a very large and positive impact on student performance.

This paper therefore presents, to our knowledge, the first solid causal evidence that a legal change in access to cannabis had a strong short run impact on productivity. It is however 
important to note that we are only looking at a very specific outcome and that our results are only a small part of the multi-dimensional societal cost-benefit analysis that should drive drug policy decision making.

The remainder of the paper is structured as follows: Section 2 provides general information on Dutch cannabis policy and presents the details of the particular change in cannabis access that occurred in Maastricht. Section 3 discusses the data on student performance that we collected at Maastricht University. Section 4 describes our empirical strategy and the various specifications we will consider. Section 5 presents the main estimation results and carries out sensitivity analysis and placebo tests. Section 6 explores underlying mechanisms and interprets the findings. Section 7 gives concluding remarks.

\section{Background: Cannabis Access in the Netherlands \& the Maastricht Case}

\subsection{The Dutch Drug Policy Approach}

For almost four decades now, the sale and consumption of cannabis for recreational use has been legal in the Netherlands. The 1976 Opium law, which forms the basis of the Dutch 'tolerance' policy, was introduced to "minimize harm done to users and their environment" (McCoun and Reuters, 1997). Practically, possession of up to 30g of cannabis (1.06 ounces) has not been a prosecutable offence since this law was passed. The government still aims to decrease demand by means of preventive campaigns and by taking legal measures against any disturbance to public order caused by cannabis sale or consumption. Although personal recreational soft-drug use is tolerated, all hard drug use is illegal, and production and illegal sale of hard and soft drugs are a severe offense and can result in jail sentences. Cannabis is usually consumed mixed with tobacco and smoked in "joints" or pipes in the Netherlands. 
The average concentration of THC in the cannabis sold in cannabis-shops was around 16.5 percent, which is almost twice as much as in cannabis confiscated in the US. ${ }^{5}$

Through legal channels, cannabis can be bought exclusively via cannabis-shops, which are strictly regulated and can only function with a license granted by the municipal authorities. Cannabis-shops are not allowed to sell more than 5 grams per person per day, and they are not allowed to have more than 500 grams at the shop premise. Furthermore, cannabis-shops are not allowed to sell any hard drugs, advertise their products or sell their products to people under the age of 18. Cannabis-shops can be shut down temporarily or permanently by the license issuing municipality if they fail to meet the regulation requirements or if they are perceived as being responsible for excessive public disturbance.

\subsection{The Maastricht Situation and the Policy Change}

Maastricht is the southernmost large city in the Netherlands. Due to its geographical proximity to Belgium, Germany, Luxembourg and especially France, it has for many years attracted a great deal of 'drug tourists', who come solely to buy (and consume) cannabis legally. As a result, it has a high density of cannabis-shops per population, second only to Amsterdam, a city infamous for international cannabis-tourism. Figure 1 presents a map which depicts the cannabis-shop density of the 443 municipality-districts of the Netherlands. Maastricht (circled) is located at the very south-east of the map in the region encased between Belgium and Germany. The city has 13 cannabis-shops for a population of about 122,000 inhabitants. A substantial part of the city's population are students: There are in total about 16,000 individuals that study at Maastricht University in any given year, and more than half of these students are non-Dutch nationals. Figure 1 also shows that not all Dutch cities (only one-third) have cannabis-shops and that the nearest one outside of Maastricht is more than 25 kilometers away.

\footnotetext{
${ }^{5}$ UNODC (2012) reports an average THC strength of 8.6 percent in confiscated cannabis.
} 
Starting from October $1^{\text {st }}, 2011$, the Maastricht association of cannabis-shop owners (VOCM), under pressure from local authorities, introduced a new policy that only allowed specific nationalities to buy cannabis on their premises. The aim of this policy was to reduce negative externalities arising from drug tourism, which the city argued constituted a public nuisance that could lead to the closure of most establishments. The policy targeted 'bad tourists', mostly individuals from France and Luxembourg, which the city council 'identified' as the populations creating the most nuisance and imposing the highest negative externalities on city residents. In a compromise, the VOCM convinced the municipality to maintain access to their cannabis-shops not only exclusively to Dutch citizens but also to individuals from the two neighboring countries, Germany and Belgium, to attempt to solve the drug-tourism problem. Retaining access rights for these three nationalities was crucial for the Maastricht establishments as these together represented on average almost 90 percent of their customers. The new policy was locally announced by retailers to inform users about two months before its official start. ${ }^{6}$ Figure 2 shows the (very discriminatory) poster that announced the policy change which cannabis-shops were required to put up on the front widow of their premises. From October $1^{\text {st }}, 2011$, anyone who was not able to present a valid Dutch, German or Belgian form of identification was refused entry to cannabis-shops. In Maastricht, all establishments have always been required to scan such documents when costumers enter to insure compliance with the minimum legal age requirement, and this was now this was also used to enforce the nationality criteria.

The policy that restricted access by nationality was in place for about seven months. From May $1^{\text {st }}$ until around June $15^{\text {th }}$, all cannabis-shops in Maastricht went on strike because of the planned introduction of a new scheme called the weed-pass ("wietpas") by the municipality. The new policy was applied to the southern part of the Netherlands and required

\footnotetext{
${ }^{6}$ The policy was announced and implemented with a relatively short notice. Therefore student application or enrolment decisions for the academic year 2011/12 could not have been affected by the policy change. Since this information was not publicly available at the time when these decisions were taken, there is no reason to believe that the student composition of Maastricht University changed due to the policy change.
} 
everyone who wanted to maintain access to cannabis-shops to register as a cannabis user at the local municipality. Registering for the weed-pass was available to any person residing in the Netherlands, independent of nationality. Around mid-June, the cannabis-shop strike ended, and after this, only residents with a valid weed-pass were allowed access to cannabisshops. We consider the strike period as a time when all individuals had limited access in our analysis but do not study the period after the weed-pass was introduced as it is impossible for us to identify which individuals are affected. Table 1 summarizes the timing of the policy changes and puts it in perspective with teaching and exam periods at Maastricht University. We describe this student performance data in detail in the next section.

\section{Data}

\subsection{Student Performance Data}

The School of Business and Economics (SBE) is one of the largest schools of Maastricht University. There are, on average, about 4,200 students enrolled at the SBE in the Bachelor, Master and $\mathrm{PhD}$ programs at any time. We obtained administrative information on all undergraduate students enrolled at the SBE during the academic years 2009/2010, 2010/2011 and 2011/2012 from the school's exam office. In total, we have 57,903 course results from 4,323 different individuals in our main sample who are, over this period, in any of the three years it takes to complete a bachelor's degree. A little more than a third of students are female, 52 percent are German, 33 percent Dutch, 6 percent Belgian and the remaining 8 percent have a different nationality (“other nationality"). The academic year at Maastricht University is divided into four regular teaching periods of two months each and two shorter skills periods of two weeks each. In total, there are 6 teaching periods per academic year for which we have course outcome information. Students take, on average, two courses at the same time in the regular periods and one course in the shorter skills periods. The SBE 
examinations office provided data on student grades and on some basic student characteristics: gender, age and nationality.

The Dutch university grading scale ranges from 1 to 10 , with 5.5 usually being the lowest passing grade. The final course grade is often calculated as the weighted average of multiple graded components, such as the final exam grade, participation grade, presentation grade and/or midterm paper grade. The graded components and their respective weights differ by course, with most courses giving most of the weight to the final exam grade. We do not observe the individual components of the final grade separately. If the final course grade of a student after taking the final exam is lower than 5.5 ( 5 in the first year), the student fails the course and has the possibility to retake the exam a second time. We observe final grades after the first and second attempt separately. For our analysis, we only use first attempt grades since the second attempts take place about two months later than the original examinations and may not be comparable to the first examinations. From this data, we create three main performance measure outcomes for our analysis: standardized grades, course passing, and course dropout. ${ }^{7}$

\subsection{Further Data Sources}

\subsubsection{Numerical vs. Non-Numerical Courses?}

The literature linking cannabis and cognitive performance has shown that numerical tasks are substantially more affected than non-numerical ones. A challenge to test this was to classify the 177 different courses available to students at the undergraduate level on whether they required numerical skills or not. To do so, we looked into the description of every single course, which is publically available online (http://code.unimaas.nl/), and classified these as

\footnotetext{
${ }^{7}$ Course dropouts are defined as students who registered for a course but either decided to drop the course at some stage throughout the teaching period, who did not fulfil their attendance requirements, or did not show up for the final exam. From the data, it is not possible to distinguish between these types of dropouts.
} 
being numerical if the following words appeared in it: math, mathematics, mathematical, statistics, statistical, theory focused. This exercise resulted in 56 courses being classified as numerical and 121 as non-numerical. As courses requiring numerical skills are more often part of the compulsory curriculum of a degree, we end up with about 35 percent of coursegrade observations being categorized as numerical. In section 6 , we split our sample along this numerical and non-numerical course line to test if we are indeed picking up the effect of cannabis consumption.

\subsubsection{Student Course Evaluations}

In addition to the scheduling and grade data, we also obtained data on students self-assessed course evaluations, which we match to the grade data using the individual student ID. We use these student course evaluations to provide evidence on some of the channels underlying our results. Two weeks before the exam, students are invited by email to evaluate the courses they are currently taking in an online questionnaire. Students receive up to three email reminders, and the questionnaire closes before the day of the exam. Students are ensured that their individual answers will not be passed on to anyone involved in the respective course. Teaching staff receive no information about the evaluation before they have submitted the final course grades to the examination office. ${ }^{8}$ The exact length and content of the online questionnaires differ by course, but they typically contain 19-25 closed questions and two open questions. For our analysis, we use the 16 core questions which are asked in most courses. ${ }^{9}$ These standard questions ask students to evaluate different course aspects like teacher performance, group functioning, course material, and general course organization, and to state the hours they spent studying outside of the course. We group these questions into 5

\footnotetext{
${ }^{8}$ This "double blind" procedure is implemented to avoid any of the two parties retaliating from negative feedback with lower grades or evaluations.

${ }^{9}$ Table A1 in the appendix shows the evaluation questions which we tried to group into different mechanism categories and which ones we group together to explore potential channels that explain changes in student performance.
} 
main categories to explore the underlying mechanism which could explain our results: "hours worked"; "feel stimulated"; “functions well”; "understand better"; and "quality improved".

\subsection{Student Performance Descriptive Statistics}

Table 2 presents the main descriptive statistics for all students in column (1), for Dutch, German and Belgian (DGB) students in column (2) and for all other students (Non-DGB) in column (3). Column (4) reports differences between these two sub-groups, and the last two columns indicate minimum and maximum values for each of the variables. The Non-DGB students display on average worse performance on all relevant indicators. They are somewhat younger and are more likely to be female than their DGB peers. The fact that these differences are always statistically significant underlines the importance of applying a difference-indifferences approach rather than performing a naïve estimation which would not account for these baseline disparities.

Figure 3 gives us the first glimpse into the existence of an effect of cannabis access restriction on course results. The figure shows course grades for treated and non-treated students over the 17 time periods we observe. To capture differences in levels between the two groups, we use two axes. The two vertical lines mark the start and the end of the discrimination policy that affected access of the Non-DGB students. We first note that there is substantial cyclicality in exam results. Importantly, the exam results of both groups of students clearly trace each other up to the period when the Non-DGB students are no longer allowed to buy cannabis in cannabis-shops. This is a good illustration of the common pretrend assumption which is necessary to validate our difference-in-differences approach. After the policy introduction, Non-DGB students appear to suddenly do much better than their DGB peers, which is a first hint that the policy might have had a positive effect on the performance 
of those who could no longer buy cannabis legally. We now present the empirical strategy we will use to formerly identify the strength of this relationship causally.

\section{$4 \quad$ Empirical Strategy}

In order to estimate the effect of legal cannabis access on student performance, we exploit a unique natural experiment that temporarily discriminated legal access to cannabis based on nationality. We apply a difference-in-differences approach across time and nationality groups. This means that we will obtain reduced form estimates of how the policy affects changes in student performance rather than (unavailable) changes in student consumption. ${ }^{10}$

The main outcome variables of interest to measure the impact of the cannabis access policy on student performance are standardized course grades and course passing rates. To test for compositional changes, we also assess whether dropout probabilities are affected. These outcomes are indicated by the dependent variable $Y$ in equation (1), which describes a simple difference-in-difference model:

$$
Y_{i t}=\alpha+\beta_{1}\left(\operatorname{NonDGB}_{i} * \operatorname{Discrim}_{t}\right)+\beta_{2} \operatorname{NonDGB}_{i}+\beta_{3} \operatorname{Discrim}_{t}+\varepsilon_{i t},
$$

where NonDGB is a dummy indicating whether a student is of another nationality than Dutch, German, or Belgian; Discrim is equal to one for the period when the discriminatory cannabisshop access policy was in place (and zero otherwise); and the interaction of these two terms enables us to get an estimate of $\beta_{1}$, the coefficient of interest. Subscript $i$ and $t$ denote, respectively, individual and time, $\alpha$ is a constant, and $\varepsilon$ an error term. To this basic

\footnotetext{
${ }^{10}$ The effect on performance is perhaps more policy relevant since changes in cannabis consumption itself might be irrelevant if they do not lead to important negative externalities for society. This reduced form approach also avoids serious measurement problems with usual measures of drug consumption since we do not have to rely on self-reported consumption or police seizures, which are likely to be correlated with changes in the legal status of this substance.
} 
specification we can also add gender and age in months to see whether adding observable individual characteristics alter results. ${ }^{11}$

We can further improve on this model by gradually adding a number of fixed effects layers to the estimation to account for unobserved course and student heterogeneity. First, we include the total number of courses taken by a student in each period, NCourses, and course fixed effects $\gamma_{j}$ for the $j=177$ different courses available to students at the bachelor level at the SBE. Second, we exploit the panel nature of our data and replace the common intercept $\alpha$ with a student specific fixed effect $\alpha_{i}$. This model is shown in equation (2):

$$
\begin{aligned}
& Y_{i j t}=\alpha_{i}+\beta_{1}\left(\text { NonDGB }_{i} * \text { Discrim }_{t}\right)+\beta_{2} \text { NonDGB }_{i}+\beta_{3} \text { Discrim }_{t}+\beta_{3} \text { Age }_{i t}+ \\
& \beta_{4} \text { NCourse }_{i t}+\gamma_{j}+\varepsilon_{i t}
\end{aligned}
$$

This within-individual estimation approach should take care of all remaining time invariant unobserved individual characteristics which could still not be accounted for in our previous models and could bias our estimates of $\beta_{1}$.

Figure 3 shows that there was substantial seasonality and a general upward trend in exam results, thus time effects might still remain as a potential confounder. The graph clearly indicates that student grades were improving over the 18 periods observed and that, within academic years, there was much cyclicality across the 6 study periods. Our final model will also include period dummies and a cubic time trend to account for the cyclicality. This model is shown in equation (3) below.

$$
\begin{aligned}
& \left.Y_{i j t}=\alpha_{i}+\beta_{1} \text { NonDGB }_{i} * \text { Discrim }_{t}\right)+\beta_{2} \text { NonDGB }_{i}+\beta_{3} \text { Discrim }_{t}+\beta_{4} \text { Age }_{i t}+ \\
& \beta_{5} \text { NCourse }_{i t}+\beta_{6} \text { Period }_{t}++\beta_{7}\left(\text { Period }_{t}\right)^{2}+\beta_{8}\left(\text { Period }_{t}\right)^{3}+\gamma_{j}+\varepsilon_{i t}
\end{aligned}
$$

\footnotetext{
${ }^{11}$ Later we also perform subgroup analyses along these dimensions to test whether different responses to the policy differ along individual characteristics.
} 
This will be our preferred specification to interpret our results on the impact of the discriminatory cannabis access policy on student performance measures. Using individual student fixed effects will rule out that the observed treatment effect of the policy is driven by a change in the student composition. We later use two modified versions of model (3) to investigate the potential effect of other individuals' treatment status on own performance. We will do this by including an interaction between the main policy effect with, in turn, the proportion of peers in the same class who are treated and a dummy of the teaching staff being DGB or not.

We again use model (3) to run placebo tests to check that the estimated effects are indeed causal and not driven by spurious correlations. Our first placebo analysis will be a "placebo in time," which switches the policy "on" one year before it was actually put in place. We also run a "placebo in nationality," where we consider Belgian students (which are statistically the most similar to Non-DGB students) as the ones with restricted access to cannabis-shops. We also obtain distinct policy effect for the numerical and non-numerical courses. Finally, we present further results using course evaluation surveys that follow this within-student difference-in-difference set up.

\section{$5 \quad$ Main Results}

\subsection{Average Policy Effect}

Table 3 reports the estimates of how the policy change affected standardized student grades. We start with the most basic specification of equation (1) in column (1) of the table and then successively build up the model with additional controls and fixed effects in columns (2) to (5). The main coefficients of interest on $N o n D G B *$ Restriction are all positive and statistically significant. They show that the students who could no longer buy cannabis legally obtained relatively better course grades during the time when the policy was in place. The coefficients actually become slightly larger as we add more controls, reaching .093 of a standard deviation 
for our most complete specification in column (5), which accounts for unobserved individual heterogeneity and time trends.

Table 4 restates this last result in the first column and then extends our analysis to two further performance measures: "passing the course" and "course dropout". Changes in the probability of passing a class are important since it will indicate whether the grade effect is concentrated at the top or bottom end of the grade distribution. An effect on passing probabilities might be economically more important than changes in grades since students that fail classes have to re-take the exam or course at a later time, which may result in delayed graduation or lead to failing to obtain a degree. We find a 4 percentage point increase in pass rates for Non-DGB students when the policy is in place, a 5.4 percent improvement from the baseline pass rate of 74.6 percent. The coefficient on the probability of dropping out is small and not statistically significant. This is an important result since it indicates that treated individuals are as likely to complete courses during the policy period as before. It also simplifies the interpretation of our results as we can reject compositional effects which could arise if we would not observe the performance of the same individuals across time.

\subsection{Sensitivity by Sub-Groups}

One way to get a better sense of where legal access to cannabis really 'bites' is to consider differences in the policy impact on the outcomes of different population sub-groups. When interpreting coefficients for different subgroups, one has to keep in mind that these may not only differ in their baseline propensity to consume cannabis, but also that they may differ in their response and compliance to the policy. Table 5 shows estimation results for the sample split by gender, age, and performance level.

The first intriguing finding is that the course grade effect seems to be much stronger for female students (.126 compared to .069 of a standard deviation). Although this difference is smaller when looking at the probability of passing courses, which changes by 4.7 percent 
for males and 5.6 percent for females because of differences in baseline pass rates. A reason for this difference might be found in difference in responses to legal status of substances across genders (Pacula, 1997) or even in stronger residual effects of cannabis consumption on test performance (Pope et al, 1997). In our case, it is also probable that the marginal young woman reacts much more negatively to having to switch to the illegal street market to purchase drugs.

The age sample split across the median age of 20.6 years (when the individual was last observed) reveals that all of the impact comes from relatively younger students. As age almost perfectly maps with year of study in the three year bachelor degree, this indicates that the performance improvements for no-access nationalities are only present in the first or second year of enrollment. This is indicative of a maturity effect, with individuals above a certain age threshold not changing consumption behavior as a result cannabis prohibition. Another possible factor is that these individuals are in the third year of their degree and have mostly established networks of DGB student with legal cannabis access who can supply them if necessary.

Next we test whether low performers, defined as students with a pre-treatment GPA below the median of 6.62, are affected differently than high performers (above median pretreatment GPA). The cannabis ban has a significant effect on the grades of high performers, but this does not change their probability of passing a course - which is not surprising since their baseline pass rate is already 94.5 percent. For low performers, however, there is a larger grade effect, and crucially the policy also very strongly changed their likelihood of passing courses, with an estimated 7.6 percent success rate increase. This is a substantial policy relevant improvement since it affects a population who may benefit the most from marginal changes in improvement in performance.

\subsection{Spillovers from Peers and Teachers}


In order to test for social multiplier effects of the policy change and affected university instructors, we also test whether classroom peer composition and teacher nationality affected student performance.

To assess the effect of treated peers, we create a variable which calculates the fraction of treated other students ( 0 to 1 ) in each teaching group within each course. ${ }^{12}$ To test if the classroom composition during the time of restricted cannabis access had an impact on own performance, we interact the basic policy effect coefficient with the fraction of treated students in each section. This measure should capture the "extra" effect on performance of having more or less peers with cannabis access. The interaction and the main policy coefficient are reported in the first two columns of Table 6 for standardized grades and probability of passing a course. The estimated impact of peer composition on grades is insignificant, but we do detect a marginal improvement in passing rates as the fraction of treated peer in the section increases. The coefficient of .21 means that a 10 percent increase in classmates that no longer have access to cannabis-shops increases the chance of passing by 2 percentage points. Interestingly, this spillover effect only exists for students who were themselves affected by the policy change, which might reflect patterns of social interaction on nationality lines inside and outside the classroom.

We also test whether student results improved because their section instructors are now performing better after their own cannabis access was restricted. In the administrative data we obtained, we can observe the teacher's nationality when it is a $\mathrm{PhD}$ student who is teaching the class, which is the case for two-thirds of sections. We use this information to form the same nationality groupings that we applied for students and test whether student performance in those classes was affected by treatment status of the teacher. ${ }^{13}$ The last two columns of Table 6 report the interaction of this dummy with the main policy effect and the

\footnotetext{
${ }^{12}$ Courses at Maastricht University are organized in multiple teaching sections called "tutorials". One section usually contains about 10-15 students. Within courses, students are randomly assigned to sections (see Feld \& Zölitz 2014).

${ }^{13}$ About one third of the university instructors have a non-DGB nationality.
} 
main difference-in-differences coefficient itself. We find no evidence of a teacher treatment effect, which is perhaps not surprising considering that results by age group had already indicated that the performance of relatively older students were not affected by the drug policy change.

\subsection{Time and Nationality Placebos}

We report the results from two falsification exercises in Table 7 which test for a potential non-policy related impact on student performance if we change the time of its introduction or the nationality of the individuals treated.

For the first falsification test, we generate a placebo policy by estimating equation (3) with the treatment period artificially placed 1 year earlier than when cannabis access restriction was actually introduced (dropping the policy period from the sample). The coefficients on both grades and pass rate for this "placebo in time" are very small and statistically insignificant. This confirms that we were not picking up some period specific effect not accounted for in our previous specifications.

Next, we consider Belgian students (instead of non-DGB) as the ones who are prohibited from entering and buying cannabis at cannabis-shops (dropping the other nonDutch nationalities actually treated from the sample). Students from Belgium are the closest in terms of observable characteristics to the treated Non-DGB. Also in this second falsification test, the coefficients on both measures of performance of this "placebo in nationality" are small and non-significant. This further supports our claim that it is the policy limiting legal cannabis access and not another unobserved event affecting certain types of students during this period which improved student performance in the short run.

\section{Underlying Mechanisms and Interpretation of Results}




\subsection{Mechanisms Driving the Findings}

Our results quite clearly show that students who lost the right to buy cannabis legally experienced important performance improvements relative to their peers who could still enter cannabis-shops. Results from the subgroup analysis appear to confirm this and are largely consistent with those individuals we would expect to be affected by the temporary cannabis prohibition. In the following, we conduct two additional exercises with the administrative data we have available to test whether our findings are consistent with the particular manner in which THC consumption affects cognitive functioning.

\subsubsection{Numerical vs. Non-Numerical Courses}

We first propose a very simple extension to our analysis of the student performance data inspired by Block and Ghoneim (1993) and Pacula et al. (2003), who find that numerical skills are more impaired by cannabis use than non-numerical skills. Consequently, if the increase in performance detected is more pronounced for courses which require more knowledge of mathematics or statistics, we can more confidently attribute it to a change in cannabis consumption. We should not expect see such a disparity in effects if the results were driven by a change in alcohol consumption caused by the policy change. If students decrease (or increase) their alcohol consumption because of complementarities (substitution) between cannabis and alcohol, we would expect numerical and non-numerical courses to be affected in a similar way. This has recently been confirmed by Carrel, Hoekstra, and West (2011), who show that access to alcohol and its consumption affect both numerical and non-numerical skills equally. Apart from cannabis use, it is very difficult to come up with any other plausible explanation why performance in these two types of courses would be affected in this systematically differential way.

Table 8 reports results for our main specification split by numerical and non-numerical categorization of courses after inspection of the content description we discussed in section 
3.2.1. The dependent variable in the first two columns is the standardized course grade. The estimates reveal that the policy effect is more than five times larger for numerical than for non-numerical courses. Since there might be differences in the average difficulty of courses that require more or less numerical skills, which may drive the grade differences, it is perhaps more sensible to focus on the effects on pass rates. These are shown in column (3) and (4) of Table 8 . We can confirm that numerical courses are on average more difficult: only two-thirds of students pass these compared to the almost 80 percent that pass non-numerical courses. Despite these baseline differences in passing rates in the different course types, the difference in the estimated policy effect remains very large, with the probability of passing being three times larger for math oriented courses than non-mathematical ones. This difference is statistically significant and a strong indicator that the improvement in performance we observe is driven by Non-DGB students altering their cannabis consumption as a result of the change in access policy.

\subsubsection{Evidence from Student Evaluations}

We now exploit the information contained in students' online course evaluation surveys, which they are asked to fill out at the end of every course. The participation rate for student course evaluations is relatively low at 37 percent, but since we investigate within-individual changes using student fixed effects, selectivity issues should play only a minor role. We match the evaluation data to students' nationality and course grades at the individual level. We have grouped the survey questions into five potential mechanism "categories": "Hours worked", "Feel Stimulated”, "Functions Well”, "Understand Better" and "Quality Improved".

Table 9 reports the coefficients of the estimated difference-in-differences policy effect on each of the potential mechanisms. A first observation is that the average number of hours per week spent studying for a course outside of the classroom does not statistically change and, if anything, slightly decreases. This is indicative that changes in the time management of 
students outside the classroom are not the main driver of our results. This suggests that the performance increase we observe is not driven by changes in student effort measured as study hours. Similarly, the domains of "stimulation," "functioning," and "quality of the course/teacher" can each be rejected as the primary reason why course results have improved. Of all channels, only the "understand" domain seems to be affected by the policy change. This underlying channel would be consistent with clinical evidence that suggests that the main effect of cannabis on human functioning is to worsen memory of things learned while 'high', or as Ranganathan and D'Souza (2006) put it in their review of the clinical literature, "THC...impairs immediate and delayed free recall of information presented after, but not before, drug administration." The fact that treated students indicate a better understanding of course material and lectures appears as further suggestive evidence that the positive performance effect we have observed here stems indeed from a decrease in cannabis consumption caused by the policy that restricted cannabis access by nationality.

\subsection{Interpretation of Findings}

\subsubsection{Relative Size of Estimated Effect}

The main finding from our most restrictive specification, which uses both student fixed effects, course fixed effects and time trends, shows that the temporary restriction of legal cannabis access increased performance by on average .093 standard deviations and raised the probability of passing a course by 5.4 percent (columns 1 and 2 of Table 4). These point estimates suggest that restricting legal access to cannabis resulted in a substantial increase in student performance. To assess the size of such an effect, it is perhaps useful to put it in perspective with other estimates of interventions aimed at the performance of college students, and in particular the effect of legal alcohol access.

Our reduced form estimates are roughly the same size as the effect as having a professor whose quality is one standard deviation above the mean (Carrell and West, 2010) or 
of the effect of being taught by a non-tenure track faculty member (Figlio, Shapiro and Soter, 2014). It is about twice as large as having a same gender instructor (Hoffmann and Oreopoulos, 2009) and of similar size as having a roommate with a one standard deviation higher GPA (Sacerdote, 2001). The effect of the cannabis prohibition we find is a bit smaller than the effect of starting school one hour later and therefore being less sleep-deprived (Carell, Maghakian \& West, 2011).

A perhaps more relevant benchmark for the comparison of our reduced form estimates is in relation to recent findings on how legal alcohol access has been found to impair college achievement. Lindo, Swensen and Waddell (2013) use an identification strategy akin to ours and show that legal alcohol access reduces course grades by .033 to .097 standard deviations when including student fixed effects. Exploiting a discontinuity at the legal drinking age for students at the United States Air Force Academy (USAFA), Carell, Hoekstra and West (2011) estimate that alcohol access causes course grades to drop by, on average, .092 standard deviations. This is remarkably close to the impact of legal cannabis access that we estimate here (.093). The reduced form point estimates of both of these studies suggest that the legal status of cannabis affects student achievements in a similar way to the legal status of alcohol.

\subsubsection{Effect on the Treated and Price Concerns}

The final policy relevant exercise we attempt here is to interpret our results in view of the proportion of individuals who actually responded to the change in legal status of cannabis: i.e., the treatment effect on the treated. A first step is to have an idea of baseline consumption rates for the particular group of individuals who were affected by the policy. To obtain rough estimates of these rates, we carried out an anonymous survey among currently enrolled students at Maastricht University ${ }^{14}$. To make the question about cannabis consumption less

\footnotetext{
${ }^{14}$ Although these are different students to the ones on which we have performance data that we use in the rest of the analysis, their baseline consumption rates are relevant for two reasons. First, their demographic
} 
salient, we embedded it in a more general questionnaire on risky behavior. In total, 192 students answered the survey, which is over 97 percent of the students present in the lectures where it was distributed. The survey question we focused on asks students if they "have ever smoked cannabis or hashish" and if so, when: "ever", "in the last 12 months", "in the last 30 days" or "in the last 7 days". 15

Interestingly, the baseline consumption rates we obtain are very similar across the treated and non-treated populations, with about 58 percent of students reporting having smoked at any point in the past year. We can consider these individuals as the potentially treated group, as the others are unlikely to change a behavior they do not participate in before the prohibition. This means that, if we assume full compliance to the policy, the treatment effect on the treated would be about .16 standard deviations $(=0.093 / 0.58)$ in course grades and a 6.9 percent increase in the pass rate. Assuming a more reasonable 50 percent compliance rate to cannabis prohibition (as estimated by Jacobi and Sovinsky, 2013), we roughly estimate a policy impact on the treated of a 0.32 standard deviations improvement in course grades and a 13.8 percent increase in the passing rate of cannabis consumers. Even if this treatment effect on the treated is somewhat overestimated due to student under-reporting baseline consumption or de-facto higher compliance rates, the effects we identify here are large and economically significant.

One potential concern remaining for the interpretation of our findings is that the drug access limitation had an effect on cannabis prices. As the partial prohibition reduced demand, one could expect prices to have gone down during this period. This could have, in turn, lead to some increase in cannabis consumption for the nationalities who are still allowed to buy the

\footnotetext{
characteristics (age, gender, and nationality) are extremely similar to the students we previously studied. Second, since the discriminatory policy was no longer in place at the time we conducted our survey, they enjoy the same legal access to cannabis as the Dutch, German and Belgian students as only some proof of residence is now needed to enter coffee-shops.

${ }^{15}$ Despite the fact that we guaranteed anonymity, it is likely that the baseline consumption rates obtained from this survey are likely to underestimate baseline consumption rates since students may not report honestly and understate their consumption levels while sitting next to their peers and in front of a lecturer.
} 
substance legally. In this case, our results would be an overestimate that captures the aggregate effect of Non-DGB smoking less because of prohibition and DGB's smoking more due to the drop in the legal price. To rule out this mechanism, we collected prices for 10 types of cannabis strains sold in 5 of the most popular coffee shops in Maastricht around the time of the policy introduction. We did this from historical postings in online forums. An average price per gram calculated from this data was found to be $€ 9.60$ before and $€ 9.70$ during the period of restrictive legal access. This suggests that the legal cannabis price was unaffected by the introduction of the policy and is therefore not a factor biasing our estimates.

\section{Conclusion}

In this paper, we have investigated how restricting cannabis access affects student achievements. We find that the performance of students who lose legal access to cannabis improves substantially. Our analysis of underlying channels suggests that the effects are specifically driven by an improvement in numerical skills, which existing literature has found to be particularly impaired by cannabis consumption. This provides perhaps the first clear causal evidence of an important positive effect on short term productivity of restricting legal access to cannabis. Our findings also imply that individuals do change their consumption behavior when the legal status of a drug changes.

We must note here that this paper only assesses the impact on one particular outcome for a specific group of individuals. The impact on examinations that require skills in math and statistics might be different from the effects on individuals in environments where performance requires different skills or is measured differently. Our estimates perhaps represent an upper bound because of the high THC concentration of Dutch cannabis compared to cannabis quality in most other countries. It could however also be argued that our estimates are lower bounds because the policy we study did not restrict access to all students who study in Maastricht, and it may have been possible to obtain illegal access to the drug through peers 
with a different nationalities who were not excluded from cannabis-shops or through other illegal channels. It is not clear whether restricting cannabis may have other severe negative consequences on, for example, crime - since it is likely to increase demand through illegal channels. It should also be noted that it is not clear from our results whether the effects of legalization and prohibition are symmetric.

We still believe that - after taking these caveats into account - our findings have potentially important policy implications for countries which are considering the relaxation of drug laws. Performance (student achievement) is perhaps more policy relevant since changes in cannabis consumption itself might be irrelevant if they do not lead to important negative externalities for society. The effects we estimate and the change in consumption behavior they imply should therefore be taken into account along with other pro and con arguments of drug legalization. As such, these new findings should therefore become integrated in the complex and multi-dimensional societal cost-benefit analysis that should drive any drug policy decision making. 


\section{References}

Adda, J., McConnell, B., \& Rasul, I. (2014). Crime and the Depenalization of Cannabis Possession: Evidence from a Policing Experiment. Journal of Political Economy, forthcoming.

Bielman, B., Nijkamp, R., Reimer J., and M. Haaijer (2013) Coffeeshops in Nederland 2012, WODC Report, Intraval, Groningen-Rotterdam.

Block, R. I., \& Ghoneim, M. M. (1993). Effects of chronic cannabis use on human cognition. Psychopharmacology, 110(1-2), 219-228.

Bossong, M. G., Jansma, J. M., van Hell, H. H., Jager, G., Oudman, E., Saliasi, E., Kahn R. S. Ramsey, N. F. (2012) Effects of 89-Tetrahydrocannabinol on Human Working Memory Function. Biological Psychiatry, 71(8), 693-699.

Bossong, M. G., Jansma, J. M., van Hell, H. H., Jager, G., Oudman, E., Saliasi, E., Kahn R. S. Ramsey, N. F. (2012) Default Mode Network in the Effects of D9Tetrahydrocannabinol (THC) on Human Executive Function, PlosOne, 8(7), e70074.

Carrell, S. E., \& West, J. E. (2010). Does professor quality matter? Evidence from random assignment of students to professors. Journal of Political Economy, 118(3), 409-432.

Carrell, S. E., Maghakian, T., \& West, J. E. (2011). A's from Zzzz's? The causal effect of school start time on the academic achievement of adolescents. American Economic Journal: Economic Policy, 3(3), 62-81.

Carrell, S.E., Hoekstra, M., West, J.E., (2011) Does drinking impair college performance? Evidence from a regression discontinuity approach. Journal of Public Economics, 95 $(1-2), 54-62$.

Cobb-Clark, D. A., Kassenboehmer, S. C., Le, T., McVicar, D., \& Zhang, R. (2015). “High”School: The Relationship between Early Marijuana Use and Educational Outcomes. Economic Record forthcoming.

Crean, R. D., Crane, N. A., and B. J. Mason (2011) An Evidence Based Review of Acute and Long-Term Effects of Cannabis Use on Executive Cognitive Functioning. Journal of Addiction Medecine, 5(1), 1-8.

Donohue III, J. J, Drug Prohibition and Its Alternatives, in Lessons from the Economics of Crime: What Reduces Offending?, P. J. Cook, S. Machin, O. Marie and G. Mastrobuoni, eds., Cambridge, MA: MIT Press, 2013. 
Feld J., and U. Zölitz (2014) On the Nature of Peer Effects in Academic Achievement. University of Gothenburg: Working papers in Economics No 596.

Figlio, D. N., Schapiro, M. O., \& Soter, K. B. (2013). Are Tenure Track Professors Better Teachers? (No. w19406). National Bureau of Economic Research.

Hall W. (2015) What has research over the past two decades revealed about the adverse health effects of recreational cannabis use?, Addiction, 110(1), 19-35

Jacobi, L. and M. Sovinsky (2013) Cannabis on Main Street? Estimating the Demand in Markets with Limited Access, $R \& R$ American Economic Review, Mimeo, University of Zurick.

Lindo, J. M., Swensen, I. D., \& Waddell, G. R. (2013). Alcohol and student performance: Estimating the effect of legal access. Journal of health economics, 32(1), 22-32.

MacCoun, R., and P. Reuter (1997). Interpreting Dutch cannabis policy: reasoning by analogy in the legalization debate. Science, 278(5335), 47-52.

Pacula, R. L. (1997) Women and Substance Use: Are Women Less Susceptible to Addiction? American Economic Review, 87(2), 454-459

Pacula, R. L., Ross, K. E., \& Ringel, J. (2003). Does Cannabis Use Impair Human Capital Formation? (No. w9963). National Bureau of Economic Research.

Pacula, R. L. and E. L. Sevigny (2014), Cannabis Liberalization Policies: Why We Can't Learn Much from Policy Still in Motion. Journal of Policy Analysis and Management, 33: $212-221$.

Pope Jr, H. G., Jacobs, A., Mialet, J. P., Yurgelun-Todd, D., \& Gruber, S. (1997). Evidence for a sex-specific residual effect of cannabis on visuospatial memory. Psychotherapy and psychosomatics, 66(4), 179-184.

Pope, H. G., Gruber, A. J., Hudson, J. I., Cohane, G., Huestis, M. A., \& Yurgelun-Todd, D. (2003). Early-onset cannabis use and cognitive deficits: what is the nature of the association?. Drug and alcohol dependence, 69(3), 303-310.

Ranganathan M. and D. C. D'Souza (2006). The acute effects of cannabinoids on memory in humans: a review, Psychopharmacology, 188(4), 425-444.

UNODC: United Nations Office of Drugs and Crimes (2012) World Drug Report, 2012, available at http://www.unodc.org/unodc/en/data-and-analysis/WDR-2012.html

Van Ours, J. C., and J. Williams (2015). Cannabis Use and Its Effects on Health, Education and Labor Market Outcomes. Journal of Economic Surveys, forthcoming. 
Figure 1: Number of Cannabis-Shops per Population across Dutch Municipalities

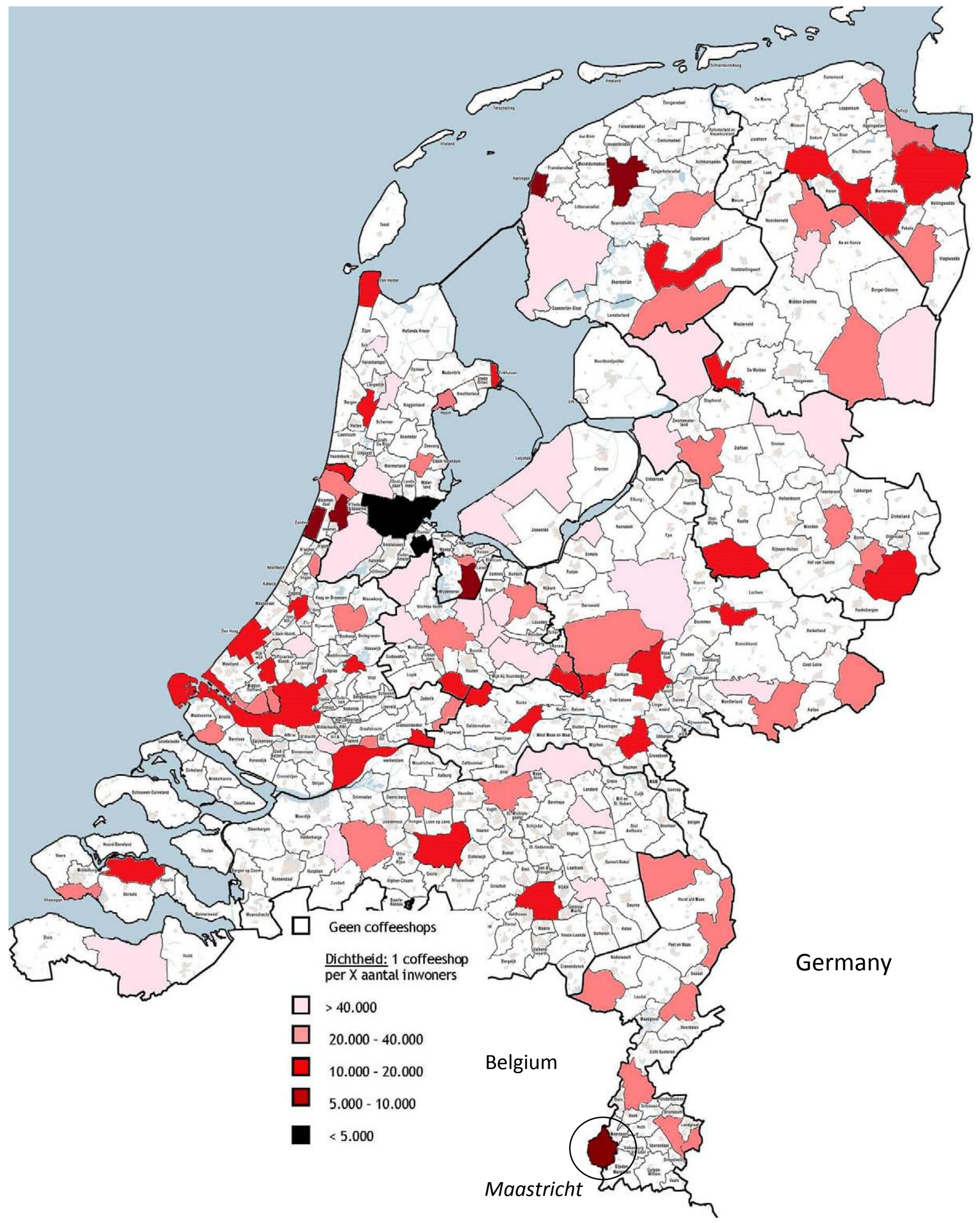

Source: Map 2.2 in Bielman et al (2012) 
Figure 2: Poster Announcing the Application of the 'Neighborhood Country Criterion' in Maastricht Cannabis-Shops on $1^{\text {st }}$ of October 2011

Vanaf 1 oktober 2011 gaan de Maastrichtse coffeeshops het buurlandcriterium toepassen A partir du 1er octobre 2011 les coffeeshops maastrichtois (VOCM) appliqueront le critère dit des pays limitrophes Ab 1 Oktober 2011 werden die Maastrichter Coffeeshops (VOCM) das Nachbarlandkriterium umsetzen Starting from 1 October 2011 the 'neighbouring country criterion' will be applied in the Maastricht coffeeshops (VOCM)

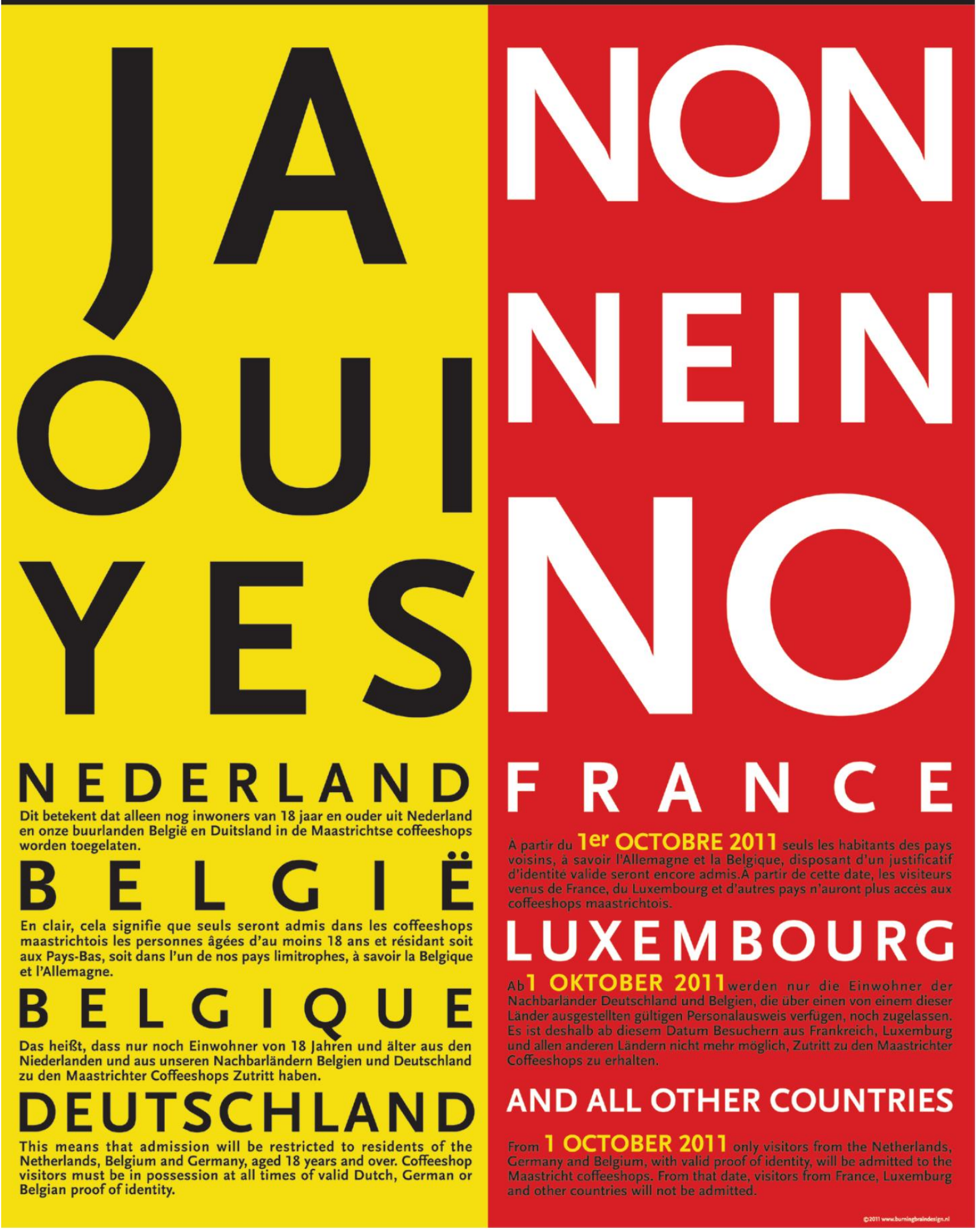


Figure 3: Course Grades for DGB and All Other Nationality Students

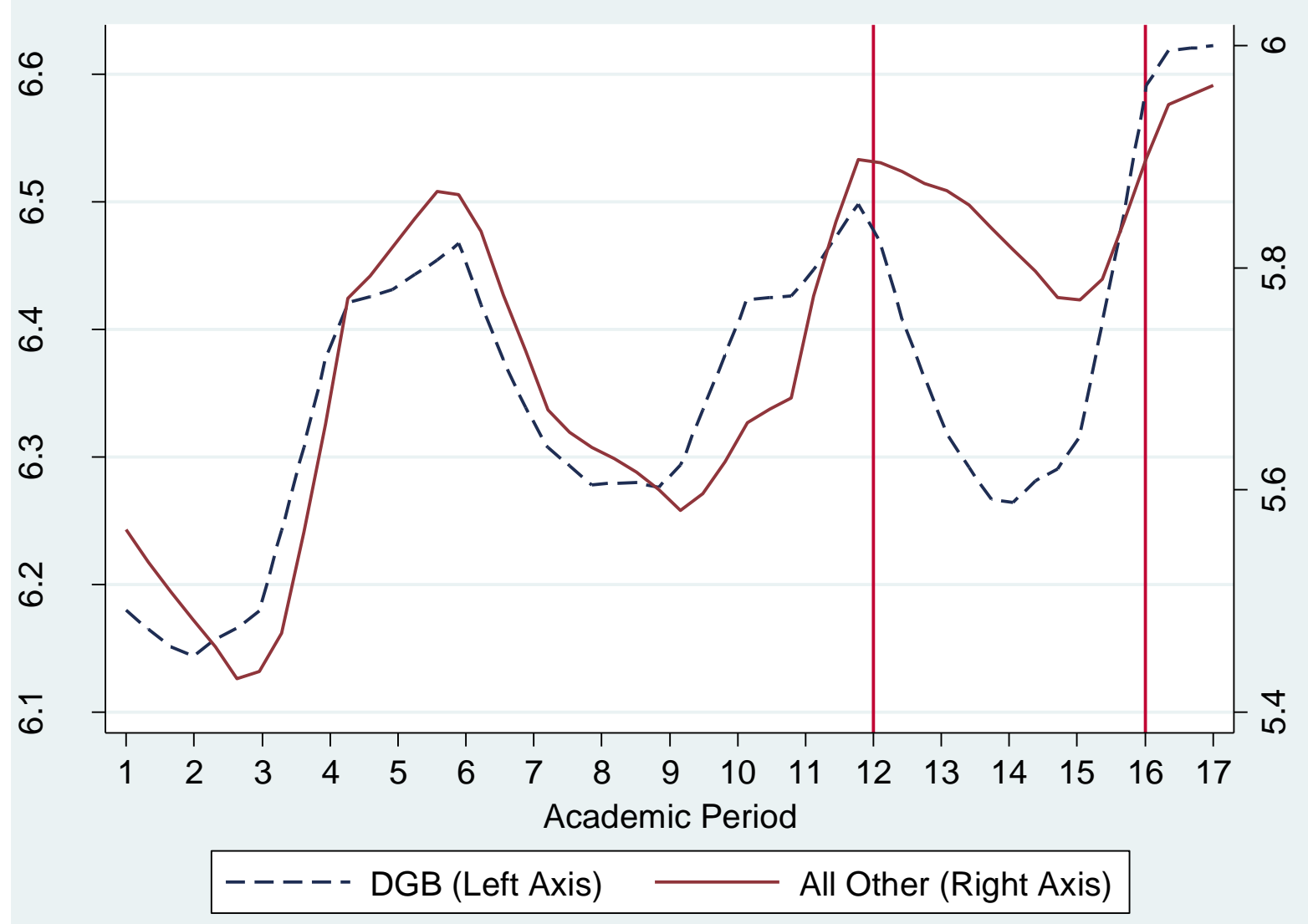

Note: The solid line represents the grades of the students treated by the cannabis prohibition. The left axis refers to the average exam grades of Dutch-German-Belgian (DGB) students, and the right axis refers to the grades of all other nationalities (Non-DGB). The two vertical lines denote the start and end of the prohibition period when the 'All Other' students had no access to cannabis-shops. 
Table 1: Timing of Changes to Cannabis Access in Maastricht and Mapping to Academic Year/Period with Student Course Grades

\begin{tabular}{|c|c|c|c|c|c|c|c|c|c|c|c|c|c|c|c|c|c|c|c|c|}
\hline Cannabis Access & \multicolumn{15}{|c|}{ All Access } & \multicolumn{3}{|c|}{ DGB only } & \multicolumn{2}{|c|}{ All Restricted } \\
\hline Total Academic Period & 1 & 2 & 3 & 4 & 5 & 6 & & & 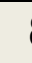 & & 9 & 10 & 11 & 12 & 13 & 14 & 15 & 16 & 17 & 18 \\
\hline Teaching Period & 1 & 2 & 3 & 4 & 5 & 6 & & 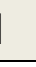 & & & 3 & 4 & 5 & 6 & 1 & 2 & 3 & 4 & 5 & 6 \\
\hline Academic Year & \multicolumn{6}{|c|}{2009 / 2010} & \multicolumn{8}{|c|}{$2010 / 2011$} & \multicolumn{6}{|c|}{$2011 / 2012$} \\
\hline Month & Sep 0 & Nov Dec & Jan $F$ & Mar & May & Jul & Sep & oc & to & & Jan & Mar & May & Jul $\mathrm{Au}$ & Sep 0 & Nov D & $\operatorname{Jan} F$ & Mar Apr & May Ju & Jul Aug \\
\hline Year & \multicolumn{2}{|c|}{2009} & \multicolumn{7}{|c|}{2010} & & \multicolumn{8}{|c|}{2011} & \multicolumn{2}{|c|}{2012} \\
\hline
\end{tabular}


Table 2: Descriptive Characteristics of All, DGB, Non-DGB Students

\begin{tabular}{lrrrrrr}
\hline \multicolumn{7}{c}{ Student Nationality } \\
& $\begin{array}{c}\text { All } \\
(\mathbf{1})\end{array}$ & $\begin{array}{c}\text { DGB } \\
\mathbf{( 2 )}\end{array}$ & $\begin{array}{c}\text { Non-DGB } \\
\mathbf{( 3 )}\end{array}$ & $\begin{array}{r}\text { Difference } \\
(\mathbf{3})-(\mathbf{2})\end{array}$ & Min & Max \\
\hline & & & & & & \\
Grade & 6.54 & 6.57 & 6.10 & $-.469^{* *}$ & 1 & 10 \\
Passed Course & .822 & .827 & .747 & $-.080^{* *}$ & 0 & 1 \\
Course Dropout & .094 & .091 & .130 & $.039^{* *}$ & 0 & 1 \\
Number of Courses & 1.99 & 1.99 & 2.06 & $.068^{* *}$ & 1 & 5 \\
Observations & 57,903 & 53,622 & 4,281 & & & \\
\hline & & & & & & \\
Female & .353 & .348 & .408 & $.045^{* *}$ & 0 & 1 \\
Age & 20.2 & 20.3 & 20.2 & $.100^{* *}$ & 16.2 & 39.7 \\
Final GPA & 6.57 & 6.61 & 5.98 & $-.526^{* *}$ & 1 & 9.75 \\
Observations & 4,419 & 4,083 & 336 & & & \\
\hline
\end{tabular}

Note: ** indicates that the differences in characteristics between Non-DGB and DGB students are significant at the 1 percent level. 
Table 3: Impact of Restricted Cannabis Access on Student Exam Scores

\begin{tabular}{lccccc}
\hline & \multicolumn{5}{c}{ Dependent Variable $=$ Standardized Grades } \\
\hline Non-DGB*Restriction & $(\mathbf{1})$ & $(\mathbf{2})$ & $(\mathbf{3})$ & $(\mathbf{4})$ & $(\mathbf{5})$ \\
\hline Non-DGB Student & $.059^{*}$ & $.058^{*}$ & $.082^{* *}$ & $.104^{* *}$ & $.093^{* *}$ \\
& $-.266^{* *}$ & $-.271^{* *}$ & $-.259^{*}$ & & $(.016)$ \\
Restriction Period & $(.090)$ & $(.088)$ & $(.100)$ & & - \\
Gender Dummy & $.026^{*}$ & $.027^{*}$ & $.042^{* *}$ & -.011 & .016 \\
Age in Months & $(.013)$ & $(.013)$ & $(.016)$ & $(.007)$ & $(.019)$ \\
Course Fixed Effects & No & Yes & Yes & No & No \\
Number of Courses & No & Yes & Yes & Yes & Yes \\
Individual Fixed Effects & No & No & Yes & Yes & Yes \\
Period Dummies \& & No & No & Yes & Yes & Yes \\
Time Trend (Cubic) & No & No & No & Yes & Yes \\
Sample Size & No & No & No & No & Yes \\
\hline
\end{tabular}

Note: Robust standard errors clustered at the nationality level reported in parenthesis. *, and ** indicate significance at the 5 and 1 percent level, respectively. 
Table 4: Impact of Restricted Cannabis Access

\section{on Various Measures of Academic Performance}

\begin{tabular}{lccc}
\hline Education Outcomes & $\begin{array}{c}(\mathbf{1}) \\
\text { Standardized } \\
\text { Grade }\end{array}$ & $\begin{array}{c}(\mathbf{2}) \\
\text { Passed } \\
\text { Course }\end{array}$ & $\begin{array}{c}(\mathbf{3}) \\
\text { Dropout } \\
\text { of Course }\end{array}$ \\
\hline Non-DGB*Restriction & $\begin{array}{c}.093^{* *} \\
(.016)\end{array}$ & $\begin{array}{c}.040^{* *} \\
(.008)\end{array}$ & $\begin{array}{c}-0.011 \\
(0.010)\end{array}$ \\
Non-DGB Student & - & - & - \\
Restriction Period & 0.016 & $.013^{* *}$ & $-0.012^{* *}$ \\
Mean of Outcome & $(0.019)$ & $(.003)$ & $(0.004)$ \\
Effect size at Mean & NA & 0.746 & 0.142 \\
All Controls and FEs & NA & 0.054 & -0.077 \\
Observations & Yes & Yes & Yes \\
\hline
\end{tabular}

Note: All specifications include the same fixed effects and controls as in the last column of Table 3 (i.e., age in months, number of courses enrolled in, teaching period dummies, a cubic in time trend, course specific fixed effects, and student specific fixed effects). Robust standard errors clustered at the nationality level are reported in parentheses. * and ** indicate significance at the 5 and 1 percent level, respectively. 
Table 5: Results by Sub-Groups

\begin{tabular}{lccc}
\hline $\begin{array}{l}\text { Sub-Group } \\
\text { Categories }\end{array}$ & $\begin{array}{c}\text { Standardized } \\
\text { Grades }\end{array}$ & $\begin{array}{c}\text { Passed } \\
\text { Course }\end{array}$ & $\begin{array}{r}\text { Sample Size, } \\
\text { Number of Students, } \\
\text { Percentage Treated }\end{array}$ \\
\hline
\end{tabular}

\section{Gender}

$\begin{array}{cccr}.069^{* *} & .036^{* *} & \text { Sample }=33,468 \\ \text { Male Students } & (.014) & (.009) & \text { N Students }=2,861 \\ & {[6.45]} & {[77.4]} & \text { \% Treated }=0.069 \\ & & \\ \text { Female Students } & .126^{* *} & 046^{* *} & \text { Sample }=18,956 \\ & (.031) & (.012) & \text { N Students }=1,558 \\ & {[6.69]} & {[81.7]} & \% \text { Treated }=0.083\end{array}$

Age

$\begin{array}{cccr} & .116^{* *} & .057^{* *} & \text { Sample }=26,317 \\ \text { Younger Students } & (.028) & (.014) & \text { N Students }=2,300 \\ & {[6.51]} & {[77.9]} & \\ & & & \\ & .024 & .005 & \text { Treated }=0.081 \\ \text { Older Students } & (.031) & (.015) & \text { Sample }=26,107 \\ & {[6.56]} & {[79.9]} & \text { \% Treated }=0.086\end{array}$

\section{Performance}

\begin{tabular}{lllr} 
& $.089 * *$ & $.047 * *$ & Sample $=27,416$ \\
Low Performers & $(.032)$ & $(.017)$ & N Students $=1,873$ \\
& {$[5.54]$} & {$[62.2]$} & $\%$ Treated $=0.081$ \\
& & \\
& $.056^{* *}$ & -.010 & Sample $=31,311$ \\
High Performers & $(.017)$ & $(.009)$ & N Students $=1,873$ \\
& {$[7.32]$} & {$[94.5]$} & $\%$ Treated $=0.088$ \\
\hline
\end{tabular}

Note: Table reports coefficients on Non-DGB*Restriction for the same specification as column (4) of Table 3 for each sub-group. For Age the sample is split between below and above the median age when last observed, 20.69 years. For Performance the sample is split between below and above the median average exam score in the period before introduction of the policy, 6.62 out of 10. The mean of pre-policy average course (nonstandardized) grade and of the pass rate by subgroup is reported in square brackets. Robust standard errors clustered at the nationality level reported in parenthesis. *,**, and *** indicate significance at the 10,5 and 1 percent level, respectively. 
Table 6: Effect of Share Treated in Class and of Nationality in Charge of Class

\begin{tabular}{lcccc}
\hline & \multicolumn{2}{c}{ Peer Effects } & \multicolumn{2}{c}{ Teacher Effects } \\
\cline { 2 - 5 } & $\begin{array}{c}(\mathbf{1}) \\
\text { Std. Grade }\end{array}$ & $\begin{array}{c}(\mathbf{2}) \\
\text { Passed } \\
\text { Course }\end{array}$ & $\begin{array}{c}(\mathbf{3}) \\
\text { Std. Grade }\end{array}$ & $\begin{array}{c}(\mathbf{4}) \\
\text { Passed } \\
\text { Course }\end{array}$ \\
\hline & & & & \\
Non-DGB* Restriction Period * & .167 & $.211^{* *}$ & & - \\
Share no-access nationality & $(.133)$ & $(.080)$ & & - \\
Non-DGB * Restriction Period * & & & -.028 & -.008 \\
Nationality of Class Teacher & - & - & $(.028)$ & $(.014)$ \\
& $.077^{* *}$ & $.021^{*}$ & $.067 * *$ & $.038^{* *}$ \\
Non-DGB * Restriction Period & $(.020)$ & $(.010)$ & $(.033)$ & $(.016)$ \\
(i.e. main policy effect) & .037 & -.015 & & - \\
Restriction Period*Share no- & $(.125)$ & $(.030)$ & - & Yes \\
access nationality & & & & 34,895 \\
All Controls \& FEs & Yes & Yes & Yes & \\
Observations & 52,395 & 52,395 & 34,895 & \\
\hline
\end{tabular}

Note: Robust standard errors clustered at the nationality level are reported in parentheses. *, **, and *** indicate significance at the 10, 5 and 1 percent level, respectively. The placebos report coefficients on NonDGB*Restriction for the same specification as column (5) of Table 3 when, respectively, the time period for treatment is changed to -1 year, and the group treated is changed to Belgians. Coefficients of interest are: standardized grades in columns 1 and 2; dropout measured by not having a grade in column 3; and the interaction of a student being NonDGB with the share of NonDGB students in the course in row 4, and with class tutor being NonDGB in row 5 . 
Table 7: Placebo in Policy Timing and Treated Group

\section{Placebo Specification}

\begin{tabular}{lcccc}
\hline & \multicolumn{2}{c}{ Policy 1 Year Earlier } & \multicolumn{2}{c}{ Belgians Treated Group } \\
\cline { 2 - 5 } & Std. Grade & Passed & Std. Grade & Passed \\
\hline \multirow{3}{*}{ Placebo Policy Effect } & -0.0129 & -0.0004 & 0.0103 & 0.0284 \\
& $(0.030)$ & $(0.013)$ & $(0.048)$ & $(0.022)$ \\
All Controls and FEs & Yes & Yes & Yes & Yes \\
Observations & 34,325 & 34,325 & 48,762 & 48,762 \\
\hline
\end{tabular}

Note: The controls and Fes included in all specifications are as in the last column of Table 3 (i.e., age in months, number of courses enrolled in, teaching period dummies, and a cubic in time trend, course specific Fes, and student specific Fes). Robust standard errors clustered at the nationality level are reported in parenthesis. * and ** indicate significance at the 5 and 1 percent level, respectively. 
Table 8: Differences between Courses Requiring More and Less Numerical Skills

\begin{tabular}{lcccc}
\hline & \multicolumn{2}{c}{ Standardized Grades } & \multicolumn{2}{c}{ Passed Course } \\
\cline { 2 - 5 } & Numerical & $\begin{array}{c}\text { Non- } \\
\text { Numerical }\end{array}$ & Numerical & $\begin{array}{c}\text { Non- } \\
\text { Numerical }\end{array}$ \\
\hline Non-DGB* Restriction & $.228^{* *}$ & $.043^{* *}$ & $.073^{* *}$ & $.023^{* *}$ \\
& $(.028)$ & $(.016)$ & $(.010)$ & $(.007)$ \\
Restriction Period & $-.183^{* *}$ & .033 & $-.055^{* *}$ & .002 \\
Mean of Outcome & $(.029)$ & $(.022)$ & $(.020)$ & $(.006)$ \\
Effect size at Mean & $\mathrm{NA}$ & $\mathrm{NA}$ & 0,663 & 0,794 \\
All Controls and FEs & $\mathrm{NA}$ & $\mathrm{NA}$ & 0,110 & 0,029 \\
Yes & Yes & Yes & Yes \\
Observations & 18,077 & 34,347 & 18,077 & 34,347 \\
\hline
\end{tabular}

Note: Robust standard errors clustered at the nationality level are reported in parenthesis. *, and ** indicate significance at the 5 and 1 percent level, respectively. 
Table 9: Exploration of Potential Channels via Student Evaluation of Courses

\begin{tabular}{lcr}
\hline $\begin{array}{l}\text { Mechanism } \\
\text { Category }\end{array}$ & Non-DGB & Survey Question(s) \\
& *Restriction & from Course Evaluation \\
\hline
\end{tabular}

Hours

Worked

$[\mathrm{N}=15,987]$

Feel

Stimulated

$[\mathrm{N}=15,937]$

\section{Functions}

Well

$[\mathrm{N}=15,997]$

Understand

Better

$[\mathrm{N}=13,520]$

Quality

Improved

$[\mathrm{N}=15,897]$
$-0.244$

$(0.376)$
"How many hours per week on average did you spend on self-study?"

"The learning materials stimulated me to start and keep on studying' \& '... stimulated discussion with my fellow students." "overall functioning of your tutor..." \& "My
tutorial group has functioned well."

"The lectures contributed to a better understanding..." \& "Working in tutorial groups helped me to better understand the subject matters of this course"

"The tutor has sufficiently mastered the course content of this course" \& "give overall grade for the quality of this course"

Note: All questions were standardized to mean zero and unit variance, then averaged within each mechanism category and again standardized to mean zero and unit variance. Robust standard errors clustered at the nationality level are reported in parenthesis. * and ** indicate significance at the 5 and 1 percent level, respectively. See Table A1 for more details about the original questions and how we categorize them into the five main channels reported here. 
APPENDIX

Table A1: Student Course Evaluation Questions

\begin{tabular}{|c|c|c|c|}
\hline Nr. & Question wording & Answering scale & Category \\
\hline 1 & $\begin{array}{l}\text { How many hours per week on the average (excluding contact hours) did you spend on self-study } \\
\text { (presentations, cases, assignments, studying literature, etc.)? }\end{array}$ & $\begin{array}{l}\text { Open question } \\
{[0-80 \text { HOURS }]}\end{array}$ & Hours Worked \\
\hline 2 & The learning materials stimulated discussion with my fellow students. & $1-5$ & Feel Stimulated \\
\hline 3 & The learning materials stimulated me to start and keep on studying. & $1-5$ & Feel Stimulated \\
\hline 4 & Evaluate the overall functioning of your tutor in this course with a grade & $1-10$ & Functions Well \\
\hline 5 & My tutorial group has functioned well. & $1-5$ & Functions Well \\
\hline 6 & The lectures contributed to a better understanding of the subject matter of this course. & $1-5$ & Understand Better \\
\hline 7 & $\begin{array}{l}\text { Working in tutorial groups with my fellow-students helped me to better understand the subject } \\
\text { matters of this course. }\end{array}$ & $1-5$ & Understand Better \\
\hline 8 & The tutor sufficiently mastered the course content. & $1-5$ & Quality Improved \\
\hline 9 & Please give an overall grade for the quality of this course & $1-10$ & Quality Improved \\
\hline
\end{tabular}

